\title{
Relationship of COVID-19 and Diabetes Mellitus
}

\author{
Kucukardali Yasar, Yalcin Arzu* and Gezer Zeynep İpek \\ Internal Medicine, Yeditepe University, Turkey
}

ISSN: 2578-0263

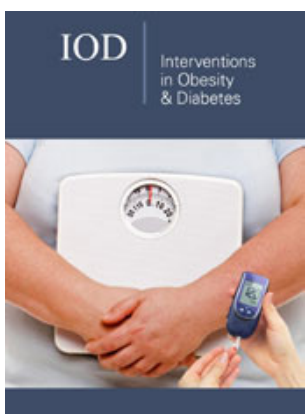

*Corresponding author: Yalcin Arzu, Yeditepe University, Ataşehir, İstanbul, Turkey

Submission: 㭗 May 12, 2020

Published: 毫June 15, 2020

Volume 4 - Issue 2

How to cite this article: Kucukardali Yasar, Yalcin Arzu, Zeynep İpek. Relationship of COVID-19 and Diabetes Mellitus. Interventions Obes Diabetes 4(2). IOD.000583. 2020. DOI: $10.31031 /$ IOD.2020.04.000583

Copyright@ Yalcin Arzu. This article is distributed under the terms of the Creative Commons Attribution 4.0 International License, which permits unrestricted use and redistribution provided that the original author and source are credited.

\begin{abstract}
When ongoing research established the relationship between Covid-19 infection and diabetes mellitus, the interest of the clinicians and the anxiety of the patients increased. This evidence-based mini-review aims to determine whether or not patients with diabetes are more prone to getting infected with Covid-19 and how this affects their clinical outcomes. Among the reported Covid-19 cases, 6-14\% outpatients, $16-25 \%$ inpatients, $32-58 \%$ ICU patients, and $31-42 \%$ cases with a mortal course had diabetes mellitus. The latest meta-analysis did not consider diabetes as a risk factor contributing to the increase in mortality of Covid-19 cases.
\end{abstract}

Keywords: Covid-19; Diabetes; Adiponectin; Cardiovascular

\section{Introduction}

Covid-19 infection, which emerged in December 2019 in China, continues to spread all over the world. Worldwide 3.5 million people have been infected and over 250.000 people have died due to Covid-19. The pathogenesis of Covid-19 infection, the mechanism with which it affects the organ systems, as well as the risk factors which exacerbate the course of the disease are still under research by the medical experts. Scientific papers of many medical journals observed underlying medical conditions such as aging, hypertension, cardiovascular disease, diabetes, obesity, cardiac failure, chronic lung disease, and cancer as severe risk factors. These findings caused a great deal of fear and concern among diabetic patients. Are diabetic patients more likely to get infected with Covid-19 than non-diabetic patients? Is the clinical course of Covid-19 infected patients with diabetes more severe? Is the mortality rate in diabetes patients higher? Is there a necessity to adjust and/or change the treatment guidelines of diabetic patients infected with Covid-19? With the help of the latest literature about Covid-19, this mini-review will try to address all the questions above and give an insight into the issue.

\section{Are diabetic patients more likely to get infected with Covid-19 than non- diabetic patients?}

Research so far has not concluded a significant difference between the rate of Covid-19 infection in diabetic and non-diabetic patients. A meta-analysis from China states that in 2108 Covid-19 infected patients, the rate of diabetes (10.3\%) [1], is similar to that of the normal population in the same region (10.9\%) [2]. In Covid-19 infected patients from Italy, the rate of diabetes was $9 \%$, and in the same region and the same age group, the rate was $11 \%$ [3]. Therefore, it would be incorrect to claim that diabetic patients are getting more infected more than the normal population. This correlation is presented in (Figure 1). 


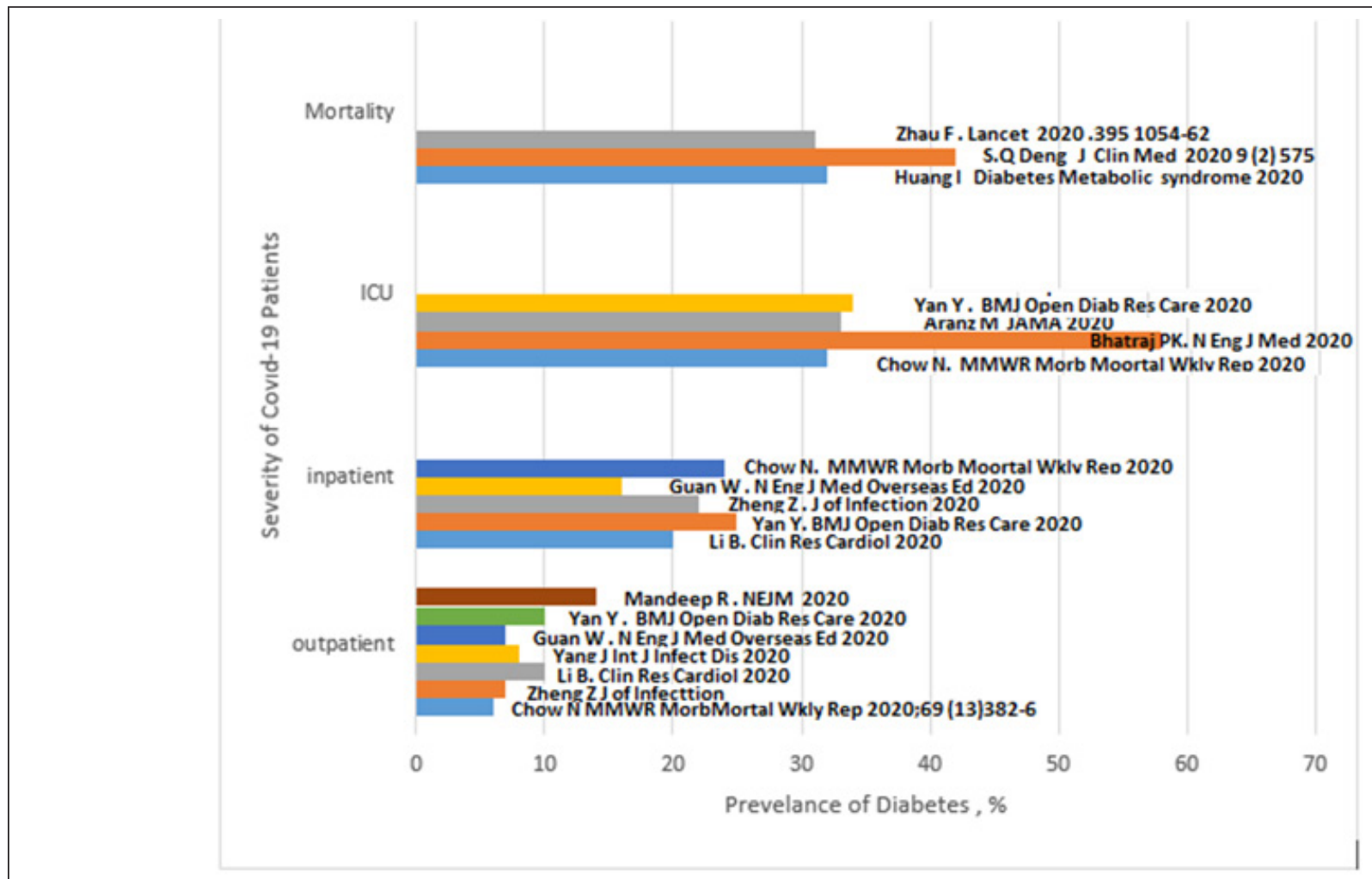

Figure 1: Relation between severity of Covid-19 infection and prevelans of diabetes.

\section{Is the clinical course of Covid-19 infected patients with} diabetes more severe?

China Disease Control Center reported that the mortality rate among 72.314 patients was $2.3 \%$, whereas, in the diabetic population it was $7.3 \%$ [4]. Moreover, it claimed that in poorlycontrolled diabetes, lymphocyte proliferation is inhibited, activation of complement cascade decreases [5,6], the viral replication increases [7], and the forced vital capacity decreases [8]. 29 diabetic inpatients who received Covid-19 treatment in China were evaluated retrospectively, and in $69 \%$ of these patients, glucose levels were high according to their 811 measured blood glucose levels [9]. Hypothetically, in diabetes, immune dysfunction forms the basis that increases the severity of the infection. Hyperglycemia leads to chemotaxis inhibition, deterioration of production of cytokines, dysfunction of phagocytosis, T-lymphocytes, and decreased microbial clearance [10]. Furthermore, increased stress levels in Covid-19 patients facilitate an increased release of glucocorticoid and catecholamines [11]. One Chinese research states that among 40 Covid-19 infected patients, 20 cases developed hyperglycemia according to diabetes criteria. This relates to the viral cytopathogenic effect on ACE-2 receptors that are abundant in the pancreas [12]. A Chinese meta-analysis, that included 30 kinds of research, established an association between diabetes, mortality, severe Covid-19 infection, and ARDS [13]. Another Chinese meta-analysis involving 1558 patients displays hypertension, diabetes and chronic obstructive lung disease, cardiovascular and cerebrovascular diseases as independent risk factors [14]. In
Yangli's research, the critical patients' data of a hospital were used. $48(25 \%)$ patients of 193 were diabetic and $66 \%$ of those diabetic patients were sent to ICU. In the same research, the diabetic patients were old and had decreased lymphocyte count, but had higher D-dimer, CRP, LDH, ferritin, and IL-6 levels than the other infected patients [15]. Type-2 diabetes patients usually have a fatty liver. In these cases, the cytokine storm is more frequent and this may increase the severity of the infection [16]. Also, increasing severity can be related to high levels of proinflammatory leptin and low anti-inflammatory adiponectin in diabetic obese patients [17]. Nonetheless, according to multivariate regression analysis, involving 8910 Asian, American, and European Covid-19 cases, diabetes was not shown as a mortality risk factor among the risk factors of Covid-19 infection [18].

Is there a necessity to adjust and/or change the treatment guidelines of diabetic patients infected with Covid-19?

There is no evidence supporting the necessity for a change in the treatment guidelines of diabetic patients infected with Covid-19. However, sulfonylureas, pioglitazone, DPP-4 inhibitors, and insulin appear safer than metformin, GLP-1 analogs, and SGLT-2 inhibitors. The anti-inflammatory effect of Metformin causes a decrease in biomarkers [19]. Moreover, if there is a GFR decrease in critical patients, metformin should be used carefully. SGLT-2 inhibitors must not be taken into consideration in severe cases when there are dehydration and risk of ketoacidosis. The administration of GLP-1 
analogs is safe in cardiovascular diseases; there is no evidence of its use in severe Covid-19 infected cases. Additionally, DPP-4 molecule levels increase in diabetic patients [20]. Since this molecule is a functional receptor against coronavirus M spike protein [20], it could increase the inflammatory reaction in Covid-19 infected patients and worsen their clinical condition [21]. DPP-4 inhibitors may contribute to decreasing the inflammation. Hypertension and hyperlipidemia often accompany diabetic patients. American and European Cardiology Associations suggest continuing angiotensin-converting enzyme inhibitors, angiotensin receptor blockers, and statins in Covid-19 infected patients [22]. In diabetic Covid-19 patients, the development of hypoglycemia should be prevented. In the Wuhan report, among diabetic patients, the rate of hypoglycemia was $10 \%$. In hypoglycemia, proinflammatory monocytes get mobilized, platelets get activated and cardiovascular mortality increases [23].

\section{Conclusion}

Diabetic patients are not more disadvantaged than the normal population in terms of getting infected with Covid-19. However, it should be noted that if a diabetic patient is infected, the clinical course is likely to be more severe. The rate of frequency of diabetes in outpatients was 6-14\%, in inpatients $16-25 \%$, in ICU patients 32 $58 \%$ and in mortal cases \%31-42. Whether diabetes increases the mortality rate or not, is still a controversial topic. In the diabetes treatment precedence should be given to insulin, DPP-4 inhibitors, sulfonylureas, and pioglitazone.

\section{References}

1. Fadini GP, Morieri ML, Longato E, Avogaro A (2020) Prevalence and impact of diabetes among people infected with SARS-CoV-2. Journal of Endocrinological Investigation 43(6): 867-869.

2. Wang L, Gao P, Zhang M, Huang Z, Zhang D, et al. (2017) Prevalence and ethnic pattern of diabetes and prediabetes in china in 2013. JAMA 317(24): 2515-2523.

3. Longato E, Di Camillo B, Sparacino G, Saccavini C, Avogaro A, et al. (2020) Diabetes diagnosis from administrative claims and estimation of the true prevalence of diabetes among 4.2 million individuals of the Veneto Region (North East Italy). Nutr Metab Cardiovasc Dis 30(1): 84-91.

4. Wu Z, McGoogan JM (2020) Characteristics of and important lessons from the coronavirus disease 2019 (COVID-19) outbreak in China: Summary of a report of 72314 cases from the Chinese center for disease control and prevention. J Am Med Assoc.

5. Moutschen MP, Scheen AJ, Lefebvre PJ (1992) Impaired immune responses in diabetes mellitus: Analysis of the factors and mechanisms involved. Relevance to the increased susceptibility of diabetic patients to specific infections. Diabete Metab 18(3): 187-201.

6. Ilyas R, Wallis R, Soilleux EJ, Townsend P, Zehnder D, et al. (2011) High glucose disrupts oligosaccharide recognition function via competitive inhibition: A potential mechanism for immune dysregulation in diabetes mellitus. Immunobiology 216(1-2): 126-131.
7. Kohio HP, Adamson AL (2013) Glycolytic control of vacuolar-type ATPase activity: A mechanism to regulate influenza viral infection. Virology 444(1-2): 301-309.

8. Lange P, Groth S, Kastrup J, Mortensen J, Appleyard M, et al. (1989) Diabetes mellitus, plasma glucose and lung function in a cross-sectional population study. Eur Respir J 2(1): 14-19.

9. Jun Zhou, Jie Tan (2020) Diabetes patients with COVID-19 need better blood glucose management in Wuhan, China. Metabolism Clinical and Experimental 107: 154216.

10. Geerlings SE, Hoepelman AI (1999) Immune dysfunction in patients with diabetes mellitus (DM). FEMS Immunol Med Microbiol 26(3-4): 259-265.

11. Wang A, Zhao W, Xu Z, Gu J (2020) Timely blood glucose management for the outbreak of 2019 novel coronavirus disease (COVID-19) is urgently needed. Diabetes Res Clin Pract.

12. Yang JK, Lin SS, Ji XJ, Guo LM (2010) Binding of SARS coronavirus to its receptor damages islets and causes acute diabetes. Acta Diabetol 47(3): 193-199.

13. Huang I, Lim MA, Pranata R (2020) Diabetes mellitus is associated with increased mortality and severity of disease in COVID-19 pneumonia-A systematic review, meta-analysis, and meta-regression. Diabetes \& Metabolic Syndrome: Clinical Research \& Reviews 14(4): 395-403.

14. Bolin Wang, Ruobao Li, Zhong Lu, Yan Huang (2020) Does comorbidity increase the risk of patients with COVID-19: Evidence from metaanalysis. AGING 12(7): 6049-6057.

15. Yan Y, Yang Y, Wang F, Huihui Ren, Shujun Zhang, et al. (2020) Clinical characteristics and outcomes of patients with severe covid-19 with diabetes. BMJ Open Diab Res Care 8(1): e001343.

16. Stefan RB, Francesco R, Kamlesh K, Geltrude M, David H, et al. (2020) Practical recommendations for the management of diabetes in patients with COVID-19. Lancet Diabetes Endocrinol 8(6): 546-550.

17. Andersen CJ, Murphy KE, Fernandez ML (2016) Impact of obesity and metabolic syndrome on immunity. Adv Nutr 7(1): 66-75.

18. Mandeep RM, Sapan SD, SreyRam K, Timothy DH, Amit NP, et al. (2020) Cardiovascular disease, drug therapy and mortality in Covid-19. NEJM.

19. Alqahtani FY, Aleanizy FS, Ali El Hadi Mohamed R, Alanazi MS, Mohamed $\mathrm{N}$, et al. (2018) Prevalence of comorbidities in cases of Middle East respiratory syndrome coronavirus: A retrospective study. Epidemiol Infect 147: 1-5.

20. Raj VS, Mou H, Smits SL, Dekkers DH, Muller MA, et al. (2013) Dipeptidyl peptidase 4 is a functional receptor for the emerging human coronavirusEMC. Nature 495: 251-254.

21. Chow N, Fleming Dutra K, Gierke R, Hall A, Hughes M, et al. (2020) Preliminary estimates of the prevalence of selected underlying health conditions among patients with coronavirus disease 2019-United States, February 12-March 28, 2020. MMWR Morb Mortal Wkly Rep 69(13): 382-386.

22. de Simone G (2020) Position statement of the ESC Council on hypertension on ACE-inhibitors and angiotensin receptor blockers.

23. Iqbal A, Prince LR, Novodvorsky P, Bernjak A, Thomas MR, et al. (2019) Effect of hypoglycemia on inflammatory responses and the response to low-dose endotoxemia in humans. J Clin Endocrinol Metab 104(4): 1187-1199. 